\title{
Sophism in the Management of Acute Aluminum Phosphide Poisoning may Cause Patient Harm
}

Sir,

In December 2016, the Indian Journal of Critical Care Medicine published our review article on the current management of acute aluminum phosphide toxicity, as well as our new proposals for therapy. ${ }^{[1]}$ One month later, in the first issue of 2017, Hassanian-Moghaddam and Zamani raised some concerns in the review. ${ }^{[2]}$ We appreciate their interest in our article and would like to address the concerns.

- In that review, we referred to a study, that reported conversion of oxyhemoglobin to methemoglobin after incubation of rat erythrocytes with phosphine. ${ }^{[1,3]}$ However, their letter referred to another study that used a co-oximeter to confirm methemoglobinemia and claimed "this could be a dyshemoglobin falsely positive for methemoglobin" and cite two of their previous publications, which were not germane to the issue ${ }^{[2]}$

- Interestingly, it seems that the authors seem to emphasize the outdated practice to washout phosphine using water soluble compounds. In fact, gastric ventilation, another approach proposed by the same authors, only assist in emitting phosphine gas produced by their conventional gastric decontamination methods. ${ }^{[2]}$ As we explained in our review, using charcoal, or potassium permanganate, is not efficacious considering their chemical properties. ${ }^{[1,4,5]}$ Another experiment by Sanaei-Zadeh and Marashi recently showed castor oil can effectively protect phosphine liberation from aluminum phosphide pellets ${ }^{[6]}$

- We believe that all efforts should be focused on resuscitation of refractory hypotension. Hence, we accept that if the patient's systemic perfusion does not improve using our new proposals, administrating glucose/insulin/ potassium could be helpful.

Lastly, we think acute aluminum phosphide poisoning is not an irremediable situation, but sophism in its management may cause patient harm. According to our previous experience, it seems that following the new proposals for therapy can improve survival. However, without a randomized controlled trial, everything is just a "claim."

\section{Financial support and sponsorship}

Nil.

\section{Conflicts of interest}

There are no conflicts of interest.
Maryam Vasheghani Farahani, Sayed Mahdi Marashi ${ }^{1}$

Department of Forensic Medicine and Clinical Toxicology, AJA University of Medical Sciences, Tehran, 'Department of Forensic Medicine and Clinical Toxicology, Shiraz University of Medical Sciences, Shiraz, Iran

Address for correspondence: Dr. Sayed Mahdi Marashi, Trauma Research Center, Emergency Room, Division of Medical Toxicology, Hazrat Ali-Asghar (p) Hospital, Meshkinfam Street, 7143918796, Shiraz University of Medical Sciences, Shiraz, Iran. E-mail: marashi@sums.ac.ir

\section{References}

1. Farahani MV, Soroosh D, Marashi SM. Thoughts on the current management of acute aluminum phosphide toxicity and proposals for therapy: An evidence-based review. Indian J Crit Care Med 2016;20:724-30.

2. Hassanian-Moghaddam H, Zamani N. Re: Thoughts on the current management of acute aluminum phosphide toxicity and proposals for therapy: An evidence-based review. Indian J Crit Care Med 2017;21:61-2.

3. Chin KL, Mai X, Meaklim J, Scollary GR, Leaver DD. The interaction of phosphine with haemoglobin and erythrocytes. Xenobiotica 1992;22:599-607.

4. Nasri Nasrabadi Z, Marashi SM. Comments on "A systematic review of aluminium phosphide poisoning”. Arh Hig Rada Toksikol 2012;63:551.

5. Marashi SM, Majidi M, Raji Asadabadi H, Nasri-Nasrabadi Z. A common misconception in the management of aluminium phosphide poisoning. Arh Hig Rada Toksikol 2013;64:475-6.

6. Sanaei-Zadeh H, Marashi SM. Gastric decontamination in aluminium phosphide poisoning: A case against the use of water-based solutions. Arh Hig Rada Toksikol 2016;67:364-5.

This is an open access article distributed under the terms of the Creative Commons Attribution-NonCommercial-ShareAlike 3.0 License, which allows others to remix, tweak, and build upon the work non-commercially, as long as the author is credited and the new creations are licensed under the identical terms.

\begin{tabular}{|l|l|}
\hline \multicolumn{3}{|c|}{ Access this article online } \\
\hline Quick Response Code: & Website: \\
& www.ijccm.org \\
& \\
&
\end{tabular}

How to cite this article: Farahani MV, Marashi SM. Sophism in the management of acute aluminum phosphide poisoning may cause patient harm. Indian J Crit Care Med 2017;21:182.

C 2017 Indian Journal of Critical Care Medicine | Published by Wolters Kluwer - Medknow 